Original Research Paper

\title{
Pengembangan Potensi Wisata Melalui Pemanfaatan Sumber Daya Alam dan Pemberdayaan Masyarakat Desa Pernek
}

\author{
Akbar Mangemba, M. Miftah Faras Z, Sultan Samer, Serli Winda Yuliani, M. Givan Fachrezzy, Dinda \\ Rama Eka Safitri, M. Adia Sopa
}

${ }^{1}$ Fakultas Peternakan, Universitas Mataram, Mataram, Indonesia

${ }^{2}$ Fakultas Hukum, Universitas Mataram, Mataram, Indonesia

${ }^{3}$ Fakultas Pertanian, Universitas Mataram, Mataram, Indonesia

${ }^{4}$ Fakultas Keguruan dan Ilmu Pendidikan, Universitas Mataram, Mataram, Indonesia

DOI: https://doi.org/10.29303/jpmpi.v4i2.702

Sitasi: Magemba, A., Faras Z, M M., Samer, S., Yuliani, S. W., Fachrezzy, M. G., Safitri, D. R. E., \& Sopa, M. A. (2021). Pengembangan Potensi Wisata Melalui Pemanfaatan Sumber Daya Alam dan Pemberdayaan Masyarakat Desa Pernek. Jurnal Pengabdian Magister Pendidikan IPA, 4(2)

\author{
Article history \\ Received: 03 Februari 2021 \\ Revised: 08 Maret 2021 \\ Accepted: 26 April 2021 \\ *Corresponding Author: M. \\ Miftah Faras Z, Fakultas \\ Hukum, Universitas Mataram, \\ Mataram, Indonesia \\ Email: \\ Miftahfaras14@gmail.com
}

\begin{abstract}
Surat keputusan bupati Sumbawa Nomor 678 tahun 2017 tentang Penetapan Desa wisata kabupaten Sumbawa memutuskan desa pernek menjadi salah satu kawasan desa wisata kabupaten Sumbawa. Pulau Sumbawa memiliki banyak sekali potensi wisata. Tidak Jarang para wisatawan yang menjadikan wisata Pulau Sumbawa menjadi destinasi wisata wajib bagi mereka. Salah satu potensi wisata yang ada di Pulau Sumbawa terletak di Desa Pernek Kecamatan Moyo Hulu. Potensi alam dan budaya yang beragam di Desa Pernek, membuat Lingkungan ini ditetapkan menjadi salah satu dari Desa wisata di Pulau Sumbawa. Sejak diresmikan sebagai Desa Wisata pada tahun 2019, jumlah kunjungan ke Desa itu meningkat cukup tinggi. Selain dapat menikmati keindahan alam dan budaya Pulau Sumbawa, para wisatawan juga dapat merasakan kuliner khas desa ini seperti Poteng, dan Manjareal. Berdasarkan hasil survei yang kami lakukan di Desa Pernek dan wawancara dengan kepala desa, bahwa diperlukan pengelolaan yang optimal. Oleh karena itu juga, kami yang tergabung dalam kelompok pelaksana kegiatan KKN di Desa Pernek akan mengadakan kegiatan Penataan Wisata Alam, sebagai program utama kami untuk menyiapkan Desa Pernek sebagai desa wisata. Hal ini sebagaimana tema atau judul kami yakni "Pengembangan Potensi Wisata Melalui Pemanfaatan Sumber Daya Alam dan Pemberdayaan Masyarakat Desa Pernek".
\end{abstract}

Keywords: Desa Wisata, Pernek.

terbaik dan banyak diminati oleh wisatawan wisatawan asing.

Pariwisata merupakan salah satu sektor yang terus dikembangkan pemerintah untuk menopang perekonomian Indonesia. Kebijakan dalam pengembangan pariwisata diatur oleh pemerintah melalui Undang-Undang No. 10 Tahun 2009 tentang Kepariwisataan. Perkembangan pariwisata di Indonesia selain lewat kebijakan pemerintah, sekarang ini juga didukung oleh kemajuan dibidang Teknologi Informasi (TI). 
Semakin mudahnya akses untuk mendapatkan informasi tentang destinasi wisata, tiket perjalanan, tempat akomodasi di daerah objek wisata. Sehingga pengembangan terhadap dunia kepariwisataan di Indonesia menjadi salah satu komoditas dan sumber pendapatan devisa negara yang cukup besar. Usaha untuk mengembangkan serta menggalakan dunia kepariwisataan kini semakin giat dilaksanakan dengan segala macam usaha untuk kemajuan di bidang kepariwisataan (Maulana \& Masrun 2009).

Wisata alam adalah bentuk kegiatan wisata alam yang memanfaatkan potensi sumber daya alam dan tata lingkungan. Wisata alam memiliki sumber daya yang berasal langsung dari alam. Selain itu, wisata alam berpotensi dan berdaya tarik bagi wisatawan serta kegiatan yang ditujukan untuk pembinaan cinta alam, baik dalam kegiatan alam maupun setelah pembudidayaan (Suwantoro 2004). Akibatnya tempat-tempat rekreasi di alam terbuka yang sifatnya masih alami dan dapat memberikan kenyamanan semakin banyak dikunjungi orang atau wisatawan. Dalam dunia pariwisata istilah Obyek wisata adalah tempat atau keadaan alam yang memiliki sumber daya wisata yang dibangun dan dikembangkan sehingga mempunyai daya tarik dan diusahakan sebagai tempat yang dikunjungi wisatawan (Musanef, 1996).

Nusa Tenggara Barat merupakan salah satu provinsi di Indonesia yang berada di bagian Barat Kepulauan Nusa Tenggara, Indonesia. Provinsi dengan sekitar 4.500.212 jiwa ini memiliki luas wilayah sekitar 20.153, $15 \mathrm{~km}^{2}$. Meski tidak tergolong padat dan besar, provinsi ini memiliki potensi wisata yang luar biasa. Tempat wisata di Nusa Tenggara Barat sangatlah beragam dan tersebar di beberapa wilayah kabupaten maupun kota.Terutama di pulau Sumbawa. Eksotisme Pulau Sumbawa sudah sangat populer di kalangan wisatawan baik domestik maupun mancanegara.

Pemerintah Kabupaten Sumbawa juga menyadari pentingnya sarana pendukung guna meningkatkan jumlah kunjungan wisatawan setiap tahunnya. Berbagai potensi yang menarik yang ada di Pulau Sumbawa diantaranya adalah wisata alam. Berbagai potensi wisata di Sumbawa ini terus dimunculkan sehingga banyak hal baru yang ditemukan.

\section{Metode}

Waktu dan tempat Program ini di lakukan di Desa Pernek Kecamatan Moyo Hulu,Kabupaten Sumbawa Besar, Provinsi Nusa Tenggara Barat. Pada Bulan Januari-Februari 2021.

Adapun Metode Pelaksanaan Kegiatan Kuliah Kerja Nyata ini menggunakan metode Pendekatan Langsung yang dikemas dalam bentuk Praktik di area wisata Desa Pernek. Adapun tahapan-tahapannya sebagai berikut :

1. Waktu dan Tempat

Program KKN mengenai "Pengembangan Potensi Wisata Melalui Pemanfaatan Sumber Daya Alam dan Pemberdayaan Masyarakat Desa Pernek" dilakukan di Desa Pernek pada Bulan Januari Februari 2021

\section{Alat dan Bahan}

Alat dan Bahan yang dibutuhkan berupa bambu, kayu, gergaji, paku, palu, cangkul, besi, cat, pilok, semen, mesin bor.

\section{Bentuk Kegiatan}

a. Tahap Awal

Tahap awal dalam kegiatan ini adalah Survey Lokasi Wisata bersama Pokdarwis Teba Tewa dan dilanjutkan dengan Kegiatan Diskusi langsung dengan Pokdarwis serta Kepala Desa Desa Pernek mengenai Program Kerja yang akan kelompok KKN kami lakukan di Desa Pernek.

\section{b. Tahap Pelaksanaan}

Tahap selanjutnya adalah Tahap Pelaksanaan dengan Menganalisis data hasil observasi dan diskusi dari tahap pertama untuk pengembangan solusi. Pengembangan solusi yang dapat kami lakukan atas permasalahan yang ada di sekitaran area wisata Desa Pernek. Dan program kerja kami merupakan solusi bagi area Wisata Desa Pernek. Dalam Program ini kami membagi jadi 2 Kegiatan yaitu Sosialisasi Program Kerja dan Pelaksanaan. Kegiatan Pertama yaitu Sosialisasi Program Kerja adalah memberikan gambaran umum kepada Pokdarwis dan Kepala Desa mengenai Kegiatan yang akan kami lakukan di Area Wisata Desa Pernek. Hal ini kami lakukan agar Pokdarwis dan Kepala desa tahu tentang Program Kerja kami dan dapat memberikan solusi dari permasalahan yang ada di area Desa wisata. 
Kegiatan Kedua adalah Pelaksanaan Program Kerja kami terhadap Area Wisata Desa Pernek.

\section{Metode}

Program ini menggunakan metode kualitatif dengan pendekatan kualitatif deskriptif karena mampu menyajikan gambaran secara detail tentang situasi, pada umumnya merupakan data yang dikumpulkan berupa kata-kata, gambar, dan buka angka. Pengambilan data pada program ini dilakukan dengan teknik observasi lapangan dan wawancara.

\section{Hasil dan Pembahasan}

Kuliah kerja nyata $(\mathrm{KKN})$ atau pengabdian mahasiswa ini telah dilakukan di desa pernek, Kecamatan Sumbawa, Kabupaten Sumbawa, Provinsi Nusa Tenggara Barat (NTB) dengan tema Desa Wisata, yang terbagi kedalam tiga kegiatan utama yaitu Pembuatan penunjuk arah menuju wisata desa pernek, pembuatan, spot foto, promosi digital, protocol covid-19, pembuatan tempat parkir, dan kerja bakti. Adapun kegiatan tambahan yaitu membantu kegiatan desa dan ikut serta dalam kegiatan desa.

Kegiatan pertama yaitu pembuatan petunjuk arah menuju tempat wisata desa pernek. Berdasarkan hasil survey lapangan, Desa pernek merupakan daerah wisata yang cukup banyak penduduk dan terdiri dari 2 dusun. Untuk menuju ke destinasi wisata desa pernek kita melewati pemukiman warga dan jalan setapak sepanjang 1.7 $\mathrm{km}$, yang mana jalan tersebut tidak memiliki petunjuk arah sehingga dapat membuat pengunjung kebingungan.

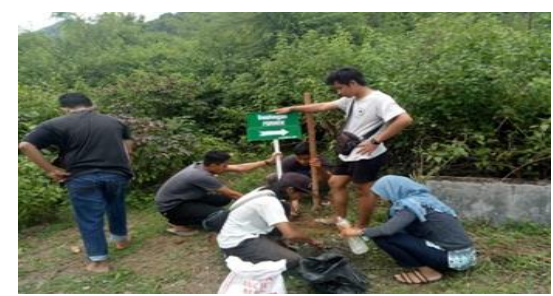

Gambar 1. Pembuatan Penunjuk Jalan

Kegiatan kedua yaitu membuat spot foto. Wisata alam yang terdapat di desa pernek merupakan tempat favorit bagi wisatawan yang datang. Untuk menciptakan daya tarik wisatawan yang dating, pembuatan spot foto ini dapat menciptakan momen indah mereka bersama keluarga, teman maupun kerabat yang datang sehingga menaikan minat wisatawan.

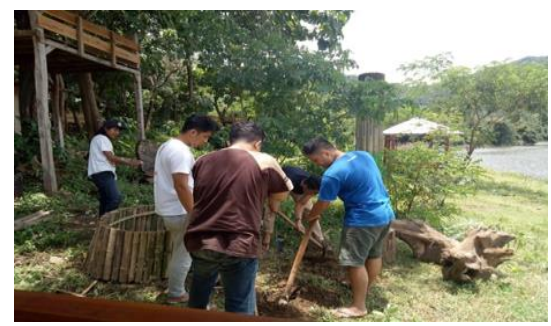

Gambar 2. pembuatan spot foto

Kegiatan ketiga adalah pembuatan Lahan Parkir.Berdasarkan survey lapangan yang kami lakukan. Di lokasi wisata masih memiliki lahan yang dapat digunakan sebagai lahan parkir untuk kendaraan pengunjung. Kami bertujuan untuk memanfaatkan lahan tersebut sebagai tempat parkir para wisatawan yang datang agar tempat wisata lebih tertata rapi dan lebih nyaman juga bagi wisatawan yang datang ke tempat wisata.

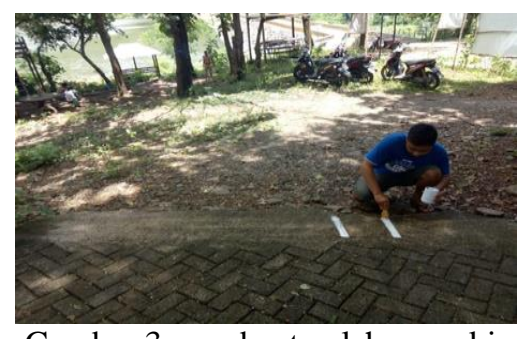

Gambar 3. pembuatan lahan parkir

Kegiatan Keempat adalah pengadaan Standar Covid 19. Karena Kesehatan dan kebersihan adalah hal utama yang perlu dijaga dan diperhatikan selama di daerah wisata. Para pengunjung serta penduduk yang ada di wajibkan untuk memakai masker, mencuci tangan dengan air dan sabun serta pemakaian hand sanitizer. Untuk itu, perlu dibuatkan dalam jumlah yang lebih banyak untuk tempat cuci tangan serta pembagian masker untuk penduduk dan pengunjung yang ada pada hari pembagian masker di wilayah wisata Desa Pernek.

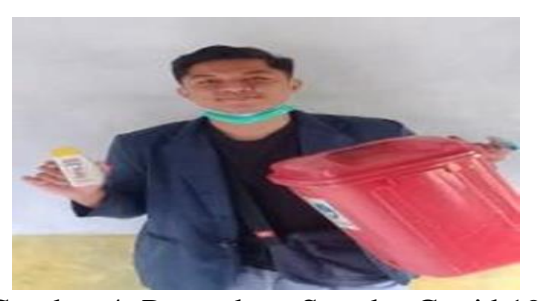

Gambar 4. Pengadaan Standar Covid 19 
Kegiatan Kelima adalah Gotong Royong di area wisata. Berdasarkan survey lapangan. Desa Pernek merupakan daerah wisata yang cukup banyak penduduknya dan terdiri dari 4 dusun. Oleh karena itu terdapat beberapa limbah atau sampah yang masih berserakan di daerah wisata Desa Pernek. Hal ini dapat disebabkan oleh beberapa faktor yaitu karena kurangnya kesadaran masyarakat akan hal tersebut dan juga bisa dikarenakan kurangnya Tempat sampah yang terdapat di Kawasan Wisata.

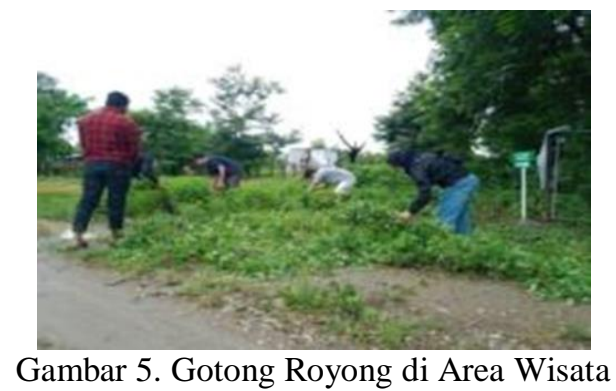

Kegiatan keenam adalah Kegiatan Penanaman 1000 Pohon. Pada tanggal 23 Januari 2021. Kami berkolaborasi dengan Pokdarwis Teba Tewa Desa Pernek untuk mengadakan penanaman 1000 pohon dalam rangka Ulang Tahun Sumbawa yang ke 62. Dan peserta yang mengikuti kegiatan sangat banyak dan beragam. Peserta yang mengikuti kegiatan ini antara lain: GPS,UTS,Pondok Pesantren Al-Kahfi, Pondok Pesantren At-Mutmainah,KPH Batulanteh, Camat Moyo Hulu.

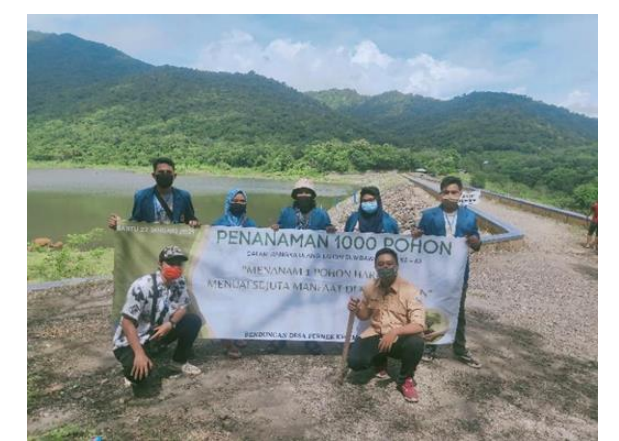

Gambar 6. Kegiatan Penanaman 1000 Pohon

Kegiatan ketujuh adalah Promosi Digital. Daerah wisata adalah hal yang paling dicari oleh masyarakat luar daerah maupun di daerah tersebut. Wisatawan yang kurang tahu mengenai informasi dan destinasi wisata yang ada pada Desa Pernek akan tahu informasi mengenai Desa Pernek dengan mengakses informasi serta update terbaru melalui Website, Instagram dan Youtube.

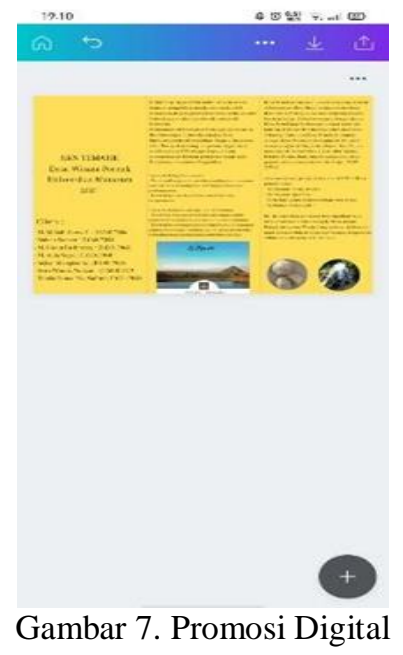

\section{Kesimpulan}

Kegiatan KKN yang kami lakukan di Desa Pernek, dapat disimpulkan bahwa permasalahan yang dihadapi oleh masyarakat desa adalah akses menuju tempat wisata tidak memadai karena jalan rusak berlumpur dan bebatuan sehingga butuh waktu lama untuk sampai ke tempat tujuan dan terdapat banyak simpangan sehingga wisatawan bingung serta masyarakat desa yang kurang perhatian dalam menjaga sarana maupun prasarana yang terdapat di lokasi wisata sehingga beberapa sarana prasarana yang rusak.

\section{Ucapan Terima Kasih}

Dalam kesempatan kali ini kami selaku mahasiswa/i KKN Universitas Mataram ingin mengucapkan terima kasih kepada pihak-pihak terkait yang telah membantu kami dalam melaksanakan KKN yakni:

1. Kepada Dosen Pendamping Lapangan Prof. Dr. Agil Al Idrus, M.Si.

2. Kepada Kepala Desa Pernek Drs. Saguni dan perangkat-perangkat desa Pernek yang telah menerima kami dengan sangat baik.

3. Kepada LPPM Universitas Mataram yang telah memfasilitasi kami selama melakukan kegiatan KKN. 


\section{Daftar Pustaka}

Maulana \& Masrun, 2009. Pengolahan Sumber Daya Alam. Bagian II. Bogor. Institut Pertanian Bogor.

Musanef. 1996. Manajemen Usaha Pariwisata di Indonesia. Jakarta : PT Toko Gunung Agung.

Suwantoro, G. 2004. Dasar-dasar Pariwisata. Yogyakarta. Andi Offset. 